\title{
Preparation of Optically Transparent Graphitic Film by Phase Transformation of $\mathrm{C}_{60}$ Molecules
}

\author{
Kazuki Ishii, Maho Iwamura, Takatoshi Yamada, ${ }^{1}$ and Toru Kuzumaki ${ }^{*}$ \\ Department of Metallurgical Engineering, Graduate School of Engineering, Tokai University, \\ 4-1-1 Kitakaname, Hiratsuka 259-1292, Japan \\ ${ }^{1}$ Nanotube Research Center, National Institute of Advanced Industrial Science and Technology, \\ 1-1-1 Higashi, Tsukuba, Ibaraki 305-8565, Japan
}

(Received September 15, 2016; accepted December 26, 2016)

Keywords: fullerene, phase transformation, transparent electroconductive film, UV irradiation, metal catalyst

We utilized the phase transformation of $\mathrm{C}_{60}$ molecules to develop a new approach for the preparation of transparent electroconductive films on glass substrates. In this study, the effect on film formation of ultraviolet (UV) irradiation in different atmospheres and in the presence of different metal catalysts was investigated. UV irradiation of the $\mathrm{C}_{60}$ films caused phase transformation by either polymerization or decomposition of $\mathrm{C}_{60}$ molecules depending upon the atmosphere. In the presence of a Ni catalyst, an optically transparent film with graphitic structure was formed. The electrical resistivity of the film was on the order of $10^{-4} \Omega \mathrm{cm}$.

The polymers of $\mathrm{C}_{60}$ molecules by UV irradiation in vacuum played a role as a solid carbon source and as a reductant, and the optically transparent graphitic film was formed by the surface reaction with $\mathrm{C}_{60}$ and the $\mathrm{Ni}$ catalyst on the glass substrate. In contrast, in the case of a $\mathrm{Cu}$ catalyst, although a film with a resistivity on the order of $10^{-6} \Omega \mathrm{cm}$ was formed, it was almost opaque and showed an undeveloped graphitic structure. A transparent film with a rough surface structure was obtained when UV irradiation was carried out at $500 \mathrm{~W}$ for $24 \mathrm{~h}$ in ambient atmosphere. In this case, interestingly, Raman spectrum mapping revealed that the region with graphitic structure was separated from the area of the $\mathrm{Cu}$ catalyst. It is believed that once the graphitic structure was formed on the $\mathrm{Cu}$ catalyst, the catalyst migrated.

\section{Introduction}

With the recent increase in the demand for flat-panel displays, the development of novel transparent electroconductive films has become necessary. Currently, the most widely used transparent electrode is the indium-tin-oxide (ITO) electrode. Indium is a rare-earth element. An increase in the consumption of such elements leads to their depletion, which is a great concern. Therefore, the development of new materials to replace ITO is required. ${ }^{(1-5)}$ Graphene is a promising candidate for such transparent electrodes. ${ }^{(6,7)}$ In general, chemical vapor deposition (CVD) of a hydrocarbon gas is used to synthesize large, uniform graphene films. ${ }^{\left({ }^{8-12}\right)}$ In recent years, a low-temperature synthesis of high-quality graphene films using a microwave CVD technique has been reported. ${ }^{(13-15)}$ However, the CVD method cannot be used for a wide range of raw materials

*Corresponding author: e-mail: kuzumaki@keyaki.cc.u-tokai.ac.jp http://dx.doi.org/10.18494/SAM.2017.1470 
and is limited to using only gaseous raw materials. ${ }^{(16)}$

In this study, we used fullerene $\left(\mathrm{C}_{60}\right)$ as the solid carbon source. ${ }^{(17)}$ Since it is possible to form a $\mathrm{C}_{60}$ monomolecular film, its thickness can be controlled at the molecular level. The spherical shelllike structure of $\mathrm{C}_{60}$ molecules is stable. However, it is known that $\mathrm{C}_{60}$ molecules are polymerized by ultraviolet (UV) or laser irradiation in the absence of oxygen. ${ }^{(18-24)}$ On the other hand, oxygenexposed $\mathrm{C}_{60}$ molecules are decomposed by UV irradiation. ${ }^{(25-28)}$ Hence, the phase transformation of $\mathrm{C}_{60}$ molecules yields different structures depending upon the presence or absence of oxygen. The intermolecular bonding of polymerized $\mathrm{C}_{60}$ is dissociated by heating at around $420 \mathrm{~K}{ }^{(24)}$ Thus, the formation of a two-dimensional (2D) graphitic structure is expected at relatively low temperatures. Hence, the utilization of the phase transformation of $\mathrm{C}_{60}$ molecules (polymerized, amorphous, and graphite phases) induced by UV irradiation and the control of the interfacial reaction between the carbon atoms and the catalyst by heat treatment is expected to contribute to the development of a novel method for the synthesis of transparent electroconductive films.

In this study, to acquire basic knowledge about the development of optically transparent graphitic films using $\mathrm{C}_{60}$, the effect of UV irradiation in the presence of different atmospheres and metal catalysts on film formation was investigated.

\section{Materials and Methods}

\subsection{Deposition of $\mathrm{C}_{60}$ thin films and $\mathrm{UV}$ irradiation}

As the source of solid carbon, the $\mathrm{C}_{60}$ thin films $(\sim 100 \mathrm{~nm})$ were deposited on quartz glass substrates $\left(15 \times 13 \times 0.5 \mathrm{~mm}^{3}\right)$ by a vacuum evaporator (JEE-400, JEOL) using $\mathrm{C}_{60}$ powder $(99.95 \%$ purity, MTR Ltd.). The as-deposited $\mathrm{C}_{60}$ thin films were UV irradiated (HE1000C, SEN Light Corp.) in a vacuum of $10^{-1} \mathrm{~Pa}$ and in ambient atmosphere. The irradiation conditions are given in Table 1.

\subsection{Preparation of optically transparent film}

In this study, $\mathrm{Ni}(\mathrm{Ni}$ process) and $\mathrm{Cu}(\mathrm{Cu}$ process) catalysts were used for the preparation of optically transparent graphitic films. The experimental details are given in the following.

\subsubsection{Ni process}

The schematic of the Ni process is shown in Fig. 1. It is expected that a Ni catalyst and the carbon atoms originating from $\mathrm{C}_{60}$ molecules make a solid-solution and then a graphitic carbon film is precipitated on the Ni catalyst. In this process, therefore, a Ni film $(\sim 20 \mathrm{~nm})$ was deposited

Table 1

UV irradiation conditions for the $\mathrm{Ni}$ and $\mathrm{Cu}$ processes.

\begin{tabular}{lcc}
\hline & Ambient atmosphere & Vacuum $\left(10^{-1} \mathrm{~Pa}\right)$ \\
\hline Ramp type & High-pressure Hg ramp \\
Radiation output (W) & $500 / 700$ & $500 / 700$ \\
Irradiation time (h) & $24 / 120$ & $24 / 18$ \\
Specimen temperature at UV irradiation $(\mathrm{K})$ & $343 / 373$ & $343 / 373$ \\
\hline
\end{tabular}


UV irradiation

(Ambient atmosphere or Vacuum of $10^{-1} \mathrm{~Pa}$ )

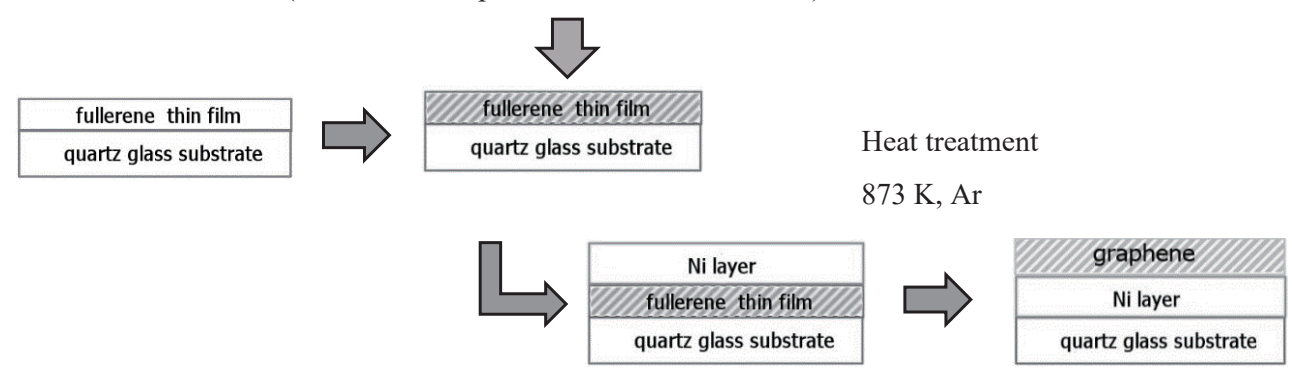

Fig. 1. Schematic of film formation in the Ni process.

on the $\mathrm{C}_{60}$ film by a sputtering system (SC-701HMC II, Sanyu Electron) with and without UV irradiation. The entire specimen was heat treated using an electric furnace (HCP-7000, ULVAC) at $873 \mathrm{~K}$ for $10 \mathrm{~min}$ in an Ar atmosphere.

\subsubsection{Cu process}

The schematic of the $\mathrm{Cu}$ process is shown in Fig. 2. In this process, the formation of the graphitic film would be dominant due to the interfacial reaction between the carbon atoms and the $\mathrm{Cu}$ catalyst. A Cu film $(\sim 300 \mathrm{~nm})$ was deposited on the quartz glass substrate by sputtering. The $\mathrm{C}_{60}$ film was then deposited on the $\mathrm{Cu}$ film under the same conditions as those used in the Ni process. The UV irradiation was carried out under the conditions given in Table 1. The heat treatment of the specimen was carried out under the same conditions as those used in the $\mathrm{Ni}$ process in an $\mathrm{Ar}+10 \% \mathrm{H}_{2}$ atmosphere.

\subsection{Structural analysis and electrical resistivity measurements}

Structural analyses of the $\mathrm{C}_{60}$ films before and after both the UV irradiation and heat treatment were conducted by laser Raman scattering spectroscopy (using a confocal Raman microscope, Renishaw). The laser wavelength was $532 \mathrm{~nm}$ and the irradiation time was $10 \mathrm{~s}$. The mean roughness of the films was measured by atomic force microscopy (SPM-9700, Shimadzu). The electrical resistivity of the films was measured by the four-probe method (K-705RH, Kyowariken).

\section{Results and Discussion}

\subsection{Polymerization of $\mathrm{C}_{60}$ molecules by $\mathrm{UV}$ irradiation}

Figures 3 and 4 show a series of photographs and the corresponding Raman scattering spectra of (a) the as-deposited $\mathrm{C}_{60}$ film, (b) $\mathrm{C}_{60}$ film exposed to UV irradiation at $500 \mathrm{~W}$ for $24 \mathrm{~h}$ in ambient atmosphere, (c) $\mathrm{C}_{60}$ film exposed to $\mathrm{UV}$ irradiation at $700 \mathrm{~W}$ for $120 \mathrm{~h}$ in ambient atmosphere, (d) $\mathrm{C}_{60}$ film exposed to UV irradiation at $500 \mathrm{~W}$ for $24 \mathrm{~h}$ in a vacuum of $10^{-1} \mathrm{~Pa}$, and (e) $\mathrm{C}_{60}$ film exposed to UV irradiation at $700 \mathrm{~W}$ for $18 \mathrm{~h}$ in a vacuum of $10^{-1} \mathrm{~Pa}$, respectively.

Figure 3(a) shows the as-deposited $\mathrm{C}_{60}$ film. The film had a light-yellow color. The other 
UV irradiation

(Ambient atmosphere)
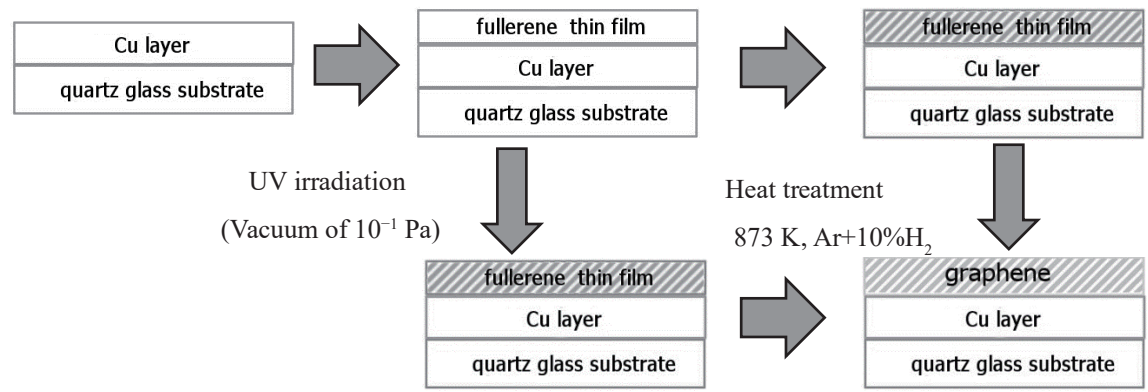

$873 \mathrm{~K}, \mathrm{Ar}+10 \% \mathrm{H}_{2}$

Fig. 2. Schematic of film formation in the $\mathrm{Cu}$ process.

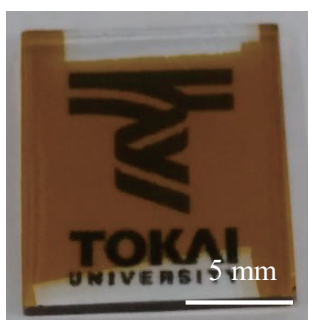

(a)

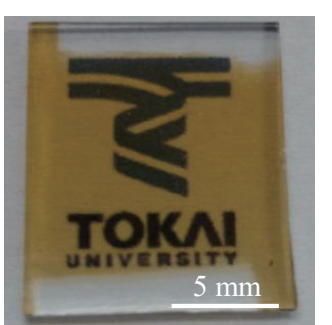

(b)

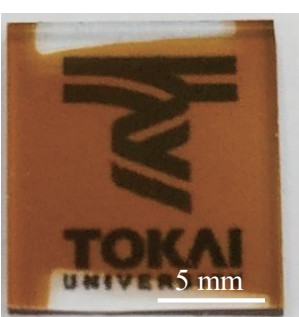

(c)

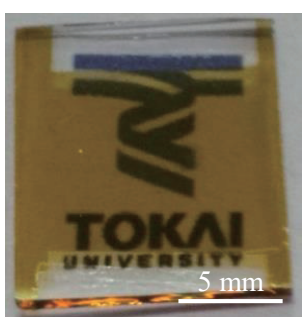

(d)

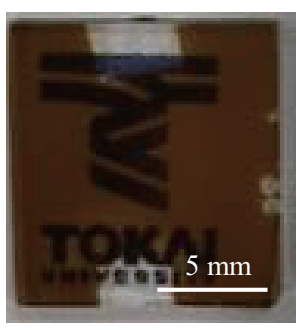

(e)

Fig. 3. (Color online) Photographs of (a) the as-deposited $\mathrm{C}_{60}$ thin film, (b) $\mathrm{C}_{60}$ film exposed to UV irradiation at $500 \mathrm{~W}$ for $24 \mathrm{~h}$ in ambient atmosphere, (c) $\mathrm{C}_{60}$ film exposed to UV irradiation at $700 \mathrm{~W}$ for $120 \mathrm{~h}$ in ambient atmosphere, (d) $\mathrm{C}_{60}$ film exposed to UV irradiation at $500 \mathrm{~W}$ for $24 \mathrm{~h}$ in a vacuum of $10^{-1} \mathrm{~Pa}$, and (e) $\mathrm{C}_{60}$ film exposed to UV irradiation at $700 \mathrm{~W}$ for $18 \mathrm{~h}$ in a vacuum of $10^{-1} \mathrm{~Pa}$.

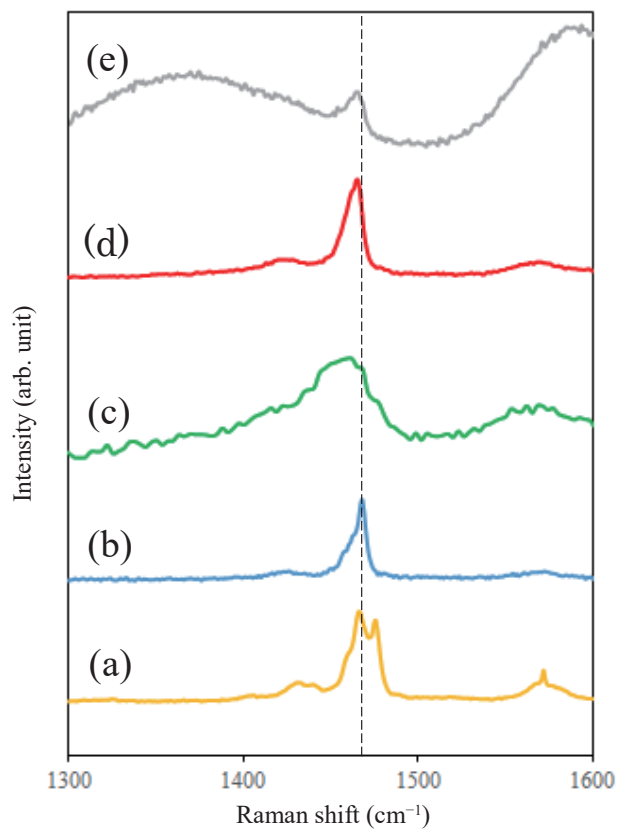

Fig. 4. (Color online) Raman scattering spectra of (a) the as-deposited $\mathrm{C}_{60}$ thin film, (b) $\mathrm{C}_{60}$ film exposed to UV irradiation at $500 \mathrm{~W}$ for $24 \mathrm{~h}$ in ambient atmosphere, (c) $\mathrm{C}_{60}$ film exposed to $\mathrm{UV}$ irradiation at $700 \mathrm{~W}$ for $120 \mathrm{~h}$ in ambient atmosphere, (d) $\mathrm{C}_{60}$ film exposed to UV irradiation at $500 \mathrm{~W}$ for $24 \mathrm{~h}$ in a vacuum of $10^{-1} \mathrm{~Pa}$, and (e) $\mathrm{C}_{60}$ film exposed to UV irradiation at $700 \mathrm{~W}$ for $18 \mathrm{~h}$ in a vacuum of $10^{-1} \mathrm{~Pa}$. The dotted line shows the position of $1469 \mathrm{~cm}^{-1}$. 
films shown in Figs. 3(b)-3(e) displayed different colors depending upon the conditions of UV irradiation. These differences were caused by the changes in the thickness and structure of the films. Each $\mathrm{C}_{60}$ film underwent partial sublimation during the UV irradiation. The structural changes in the $\mathrm{C}_{60}$ films were examined in Raman spectra near the $\mathrm{Ag}_{\mathrm{g}}(2)$ pentagonal pinch mode, which broadens and shifts from 1469 to $1458 \mathrm{~cm}^{-1}$ as the transformation proceeds. ${ }^{(18-20)}$ Figures 4(b) and 4(c) show the Raman spectra of the $\mathrm{C}_{60}$ films exposed to UV irradiation in ambient atmosphere. A peak at around $1469 \mathrm{~cm}^{-1}$, which is the characteristic peak of a pristine $\mathrm{C}_{60}$ film, was observed in both spectra. The intensity of this peak (where location is represented by a dotted line) tended to increase with an increase in the UV irradiation output. Figures 4(d) and 4(e) show the Raman spectra of the films exposed to UV irradiation in vacuum. From the figures it can be seen that the intensity of the characteristic peak of $C_{60}$ films observed at around $1469 \mathrm{~cm}^{-1}$ tended to shift slightly to lower wave-numbers with an increase in the UV irradiation output.

These results indicate that the UV irradiation in vacuum resulted in the polymerization of $\mathrm{C}_{60}$ molecules, whereas that in ambient atmosphere resulted in the decomposition of $\mathrm{C}_{60}$ molecules. Under ambient atmosphere, the polymerization of $\mathrm{C}_{60}$ molecules was prevented because of oxygen adsorption or intercalation between the $\mathrm{C}_{60}$ molecules. ${ }^{(25)}$ Oxygen inhibited the polymerization of $\mathrm{C}_{60}$ molecules. It has been reported that the oxygen-rich phase obtained by irradiation with UV or visible light is usually referred to as "phototransformed" to differentiate it from the oxygen-free $\mathrm{C}_{60}$ polymer. ${ }^{(25-27)}$ The presence of oxygen molecules promoted the destruction of $\mathrm{C}_{60}$ molecules into a glassy graphitic phase. ${ }^{(28,29)}$ The experimental results demonstrate that the UV irradiation of the $\mathrm{C}_{60}$ films resulted in a phase transformation by either polymerization or decomposition of $\mathrm{C}_{60}$ molecules depending upon the atmosphere.

\subsection{Ni process}

Figures $5(\mathrm{a})-5(\mathrm{~d})$ show photographs of the films obtained after the heat treatment with the $\mathrm{Ni}$ catalyst. The mean roughness of these films was approximately $20-50 \mathrm{~nm}$ whereas that of the films before the heat treatment was approximately $6 \mathrm{~nm}$. This result suggests that the surface structure was changed by the heat treatment. The optical transparency of the films exposed to UV irradiation in the ambient atmosphere shown in Figs. 5(a) and 5(b) was slightly higher than that of the films exposed to UV irradiation in the vacuum shown in Figs. 5(c) and 5(d). However, the

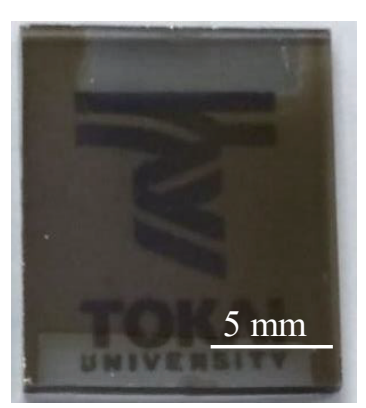

(a)

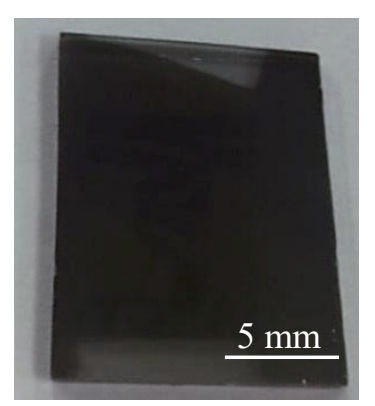

(b)

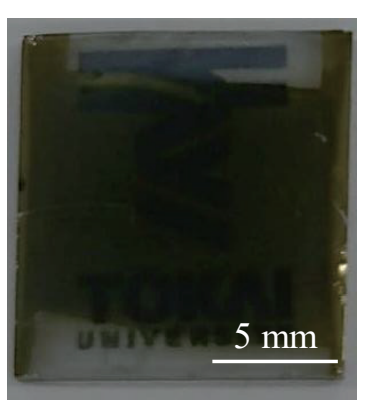

(c)

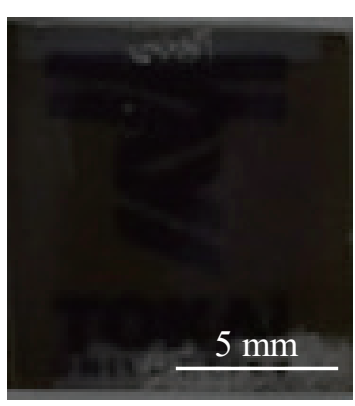

(d)

Fig. 5. (Color online) Photographs of the films obtained after heat treatment with the Ni catalyst. (a) The $\mathrm{C}_{60}$ film exposed to UV irradiation at $500 \mathrm{~W}$ for $24 \mathrm{~h}$ in ambient atmosphere, (b) $\mathrm{C}_{60}$ film exposed to UV irradiation at 700 $\mathrm{W}$ for $120 \mathrm{~h}$ in ambient atmosphere, (c) $\mathrm{C}_{60}$ film exposed to UV irradiation at $500 \mathrm{~W}$ for $24 \mathrm{~h}$ in a vacuum of $10^{-1}$ $\mathrm{Pa}$, and (d) $\mathrm{C}_{60}$ film exposed to $\mathrm{UV}$ irradiation at $700 \mathrm{~W}$ for $18 \mathrm{~h}$ in a vacuum of $10^{-1} \mathrm{~Pa}$. 
Raman spectra shown in Figs. 6(c) and 6(d) show that the graphitization of the films exposed to UV irradiation in the vacuum was more advanced. The electrical resistivities of the films exposed to UV irradiation in ambient atmosphere and vacuum were on the order of $10^{-3}$ and $10^{-4} \Omega \mathrm{cm}$, respectively.

It is known that a $\mathrm{Ni}$ catalyst and the carbon atoms originating from $\mathrm{C}_{60}$ molecules make a solid solution and carbon is then precipitated as a thin film with a graphitic structure. In this study, the carbon in Ni solubility was estimated to be less than $0.1 \%$ because the heat treatment temperature was low $(873 \mathrm{~K})$. Thus, it can be stated that the graphitic structure was actually formed by the interfacial reaction between the $\mathrm{C}_{60}$ molecules and the $\mathrm{Ni}$ atoms. The optical transparency of the films exposed to UV irradiation in ambient atmosphere was relatively high. However, the films exposed to UV irradiation under vacuum showed higher graphitization (as observed from the 2D spectrum near $2680 \mathrm{~cm}^{-1}$ ) and lower resistivity. To understand these results, it is necessary to consider the influence of UV irradiation. In ambient atmosphere, oxygen was absorbed or intercalated between $\mathrm{C}_{60}$ molecules, and UV irradiation prevented the polymerization of $\mathrm{C}_{60}$ molecules. ${ }^{(25)}$ As already mentioned, the presence of oxygen molecules promotes the destruction of $\mathrm{C}_{60}$ molecules into a glassy graphitic phase. Here, since the polymerization of $\mathrm{C}_{60}$ molecules was inhibited, their destruction and sublimation as a solid carbon source was promoted by UV irradiation in ambient atmosphere.

UV irradiation in vacuum, on the other hand, is expected to yield a $\mathrm{C}_{60}$ dimer by a $2+2$ cycloaddition reaction. ${ }^{(19,24)}$ During the heat treatment, some of the cross-links dissociated, and then the $\mathrm{C}_{60}$ molecules with opened shells easily underwent an interfacial reaction with the $\mathrm{Ni}$ catalyst. In the $\mathrm{C}_{60}$ films exposed to $\mathrm{UV}$ irradiation in vacuum, the sublimation of $\mathrm{C}_{60}$ molecules during the heat treatment was less than for the films exposed to UV irradiation in ambient

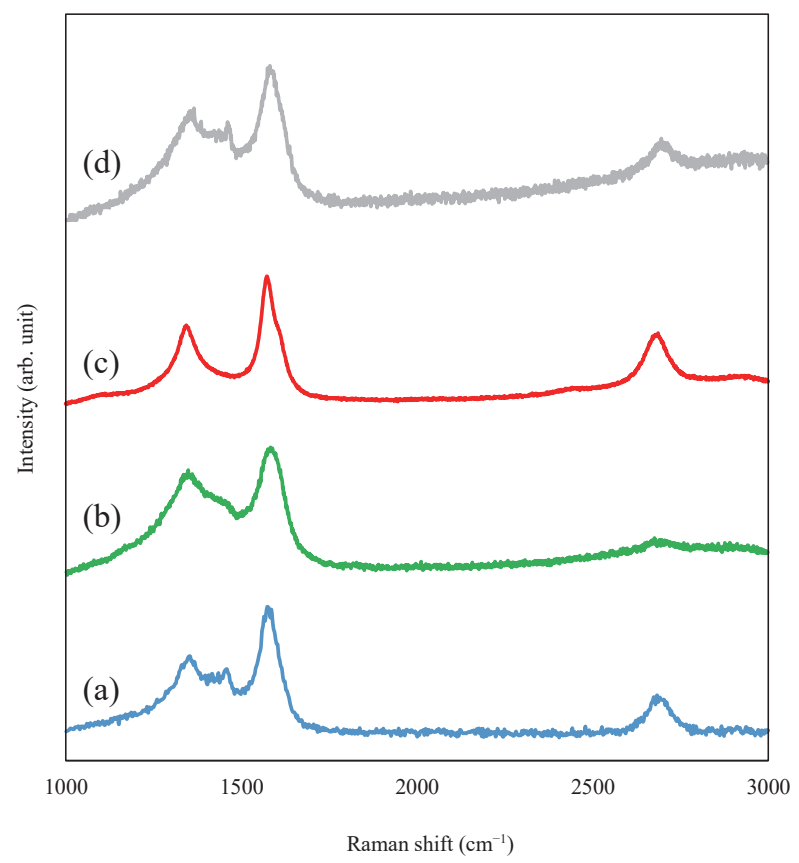

Fig. 6. (Color online) Raman spectra of the films obtained after heat treatment with the Ni catalyst. (a) The $\mathrm{C}_{60}$ film exposed to UV irradiation at $500 \mathrm{~W}$ for $24 \mathrm{~h}$ in an ambient atmosphere, (b) $\mathrm{C}_{60}$ film exposed to UV irradiation at $700 \mathrm{~W}$ for $120 \mathrm{~h}$ in an ambient atmosphere, (c) $\mathrm{C}_{60}$ film exposed to $\mathrm{UV}$ irradiation at $500 \mathrm{~W}$ for $24 \mathrm{~h}$ in a vacuum of $10^{-1} \mathrm{~Pa}$, and (d) $\mathrm{C}_{60}$ film exposed to UV irradiation at $700 \mathrm{~W}$ for $18 \mathrm{~h}$ in a vacuum of $10^{-1} \mathrm{~Pa}$. 
atmosphere. This is attributed to the polymerization of $\mathrm{C}_{60}$ molecules where the films were exposed to UV irradiation in vacuum.

In the Ni process without UV irradiation, an undeveloped graphitic structure was obtained. UV irradiation is essential for the formation of graphitic films from $\mathrm{C}_{60}$ films. The results suggest that UV irradiation in vacuum and a subsequent heat treatment using a $\mathrm{Ni}$ catalyst contributes to the formation of transparent films. However, optimization of the thickness of the $\mathrm{C}_{60}$ and $\mathrm{Ni}$ catalyst films exposed to UV irradiation in vacuum is required.

\subsection{Cu process}

The as-deposited $\mathrm{C}_{60}$ thin film formed on the $\mathrm{Cu}$ film substrate was opaque and showed an almost coppery color. Figures 7 and 8 show a series of photographs and the corresponding Raman scattering spectra, respectively, of (a) the $\mathrm{C}_{60}$ film exposed to UV irradiation at $500 \mathrm{~W}$ for $24 \mathrm{~h}$ in ambient atmosphere, (b) $\mathrm{C}_{60}$ film exposed to $\mathrm{UV}$ irradiation at $700 \mathrm{~W}$ for $120 \mathrm{~h}$ in ambient atmosphere, (c) $\mathrm{C}_{60}$ film exposed to UV irradiation at $500 \mathrm{~W}$ for $24 \mathrm{~h}$ in a vacuum of $10^{-1} \mathrm{~Pa}$, and (d) $\mathrm{C}_{60}$ film exposed to UV irradiation at $700 \mathrm{~W}$ for $18 \mathrm{~h}$ in a vacuum of $10^{-1} \mathrm{~Pa}$ when the heat treatment with a reductive gas flow $\left(10 \% \mathrm{H}_{2} / \mathrm{Ar}\right)$ was carried out in the presence of the Cu catalyst.

The film obtained by UV irradiation at $500 \mathrm{~W}$ for $24 \mathrm{~h}$ in ambient atmosphere followed by a heat treatment exhibited optical transparency, as shown in Fig. 7(a). However, the films shown in Figs. 7(b)-7(d) were inhomogeneous and opaque. The Raman spectra in Figs. 8(a)-8(d) show that every film did not exhibit a distinct $2 \mathrm{D}$ peak near $2680 \mathrm{~cm}^{-1}$. This suggests that the graphitic structure was undeveloped. Within this experiment, the resistivity of almost all the films exposed to UV irradiation was on the order of $10^{-6} \Omega \mathrm{cm}$. The resistivity of the films was comparable to that of the copper, so that, during the electrical resistivity measurement, the probes penetrated the graphitic film and may have measured the resistivity of the copper catalyst.

In the $\mathrm{Cu}$ process, the graphitic film was synthesized by the interfacial reaction between the carbon atoms and the $\mathrm{Cu}$ catalyst. ${ }^{(8,29)}$ The reduction of the $\mathrm{Cu}$ catalyst was expected during heat treatment by a flow of $10 \% \mathrm{H}_{2}$ in $\mathrm{Ar}$ gas in the $\mathrm{Cu}$ process. ${ }^{(19)}$ In this study, unfortunately, an undeveloped graphitic structure was obtained. There are two reasons for this: the first is the effect of $\mathrm{UV}$ irradiation and the $\mathrm{Cu}$ catalyst on the formation of the $\mathrm{C}_{60}$ films. Unlike the case when a quartz glass substrate was used, the surface oxide film of the $\mathrm{Cu}$ catalyst $\left(\mathrm{Cu}_{2} \mathrm{O}\right)$ was reduced by

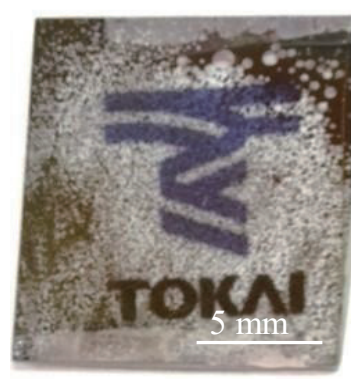

(a)

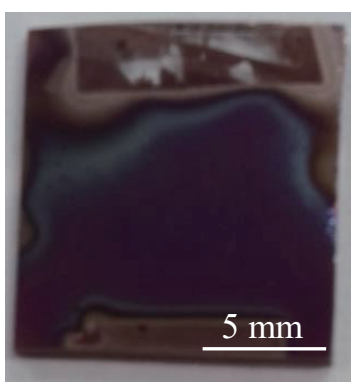

(b)

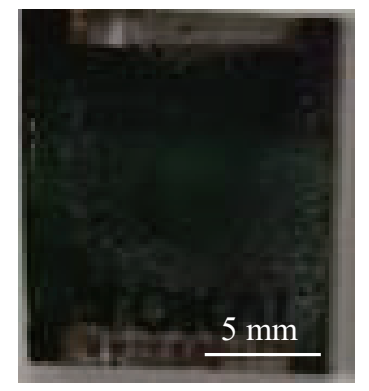

(c)

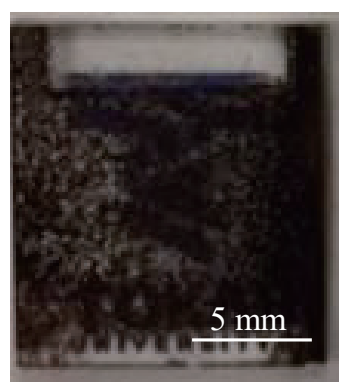

(d)

Fig. 7. (Color online) Photographs of the films obtained after heat treatment with the Cu catalyst. (a) The $\mathrm{C}_{60}$ film exposed to UV irradiation at $500 \mathrm{~W}$ for $24 \mathrm{~h}$ in ambient atmosphere, (b) $\mathrm{C}_{60}$ film exposed to UV irradiation at 700 $\mathrm{W}$ for $120 \mathrm{~h}$ in ambient atmosphere, (c) $\mathrm{C}_{60}$ film exposed to $\mathrm{UV}$ irradiation at $500 \mathrm{~W}$ for $24 \mathrm{~h}$ in vacuum of $10^{-1}$ $\mathrm{Pa}$, and (d) $\mathrm{C}_{60}$ film exposed to $\mathrm{UV}$ irradiation at $700 \mathrm{~W}$ for $18 \mathrm{~h}$ in a vacuum of $10^{-1} \mathrm{~Pa}$. 


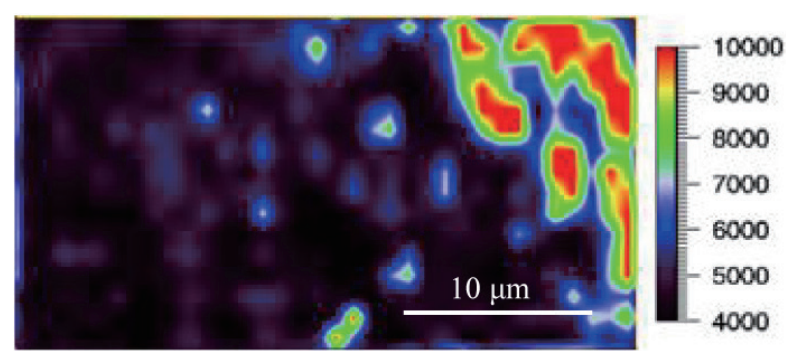

(a)

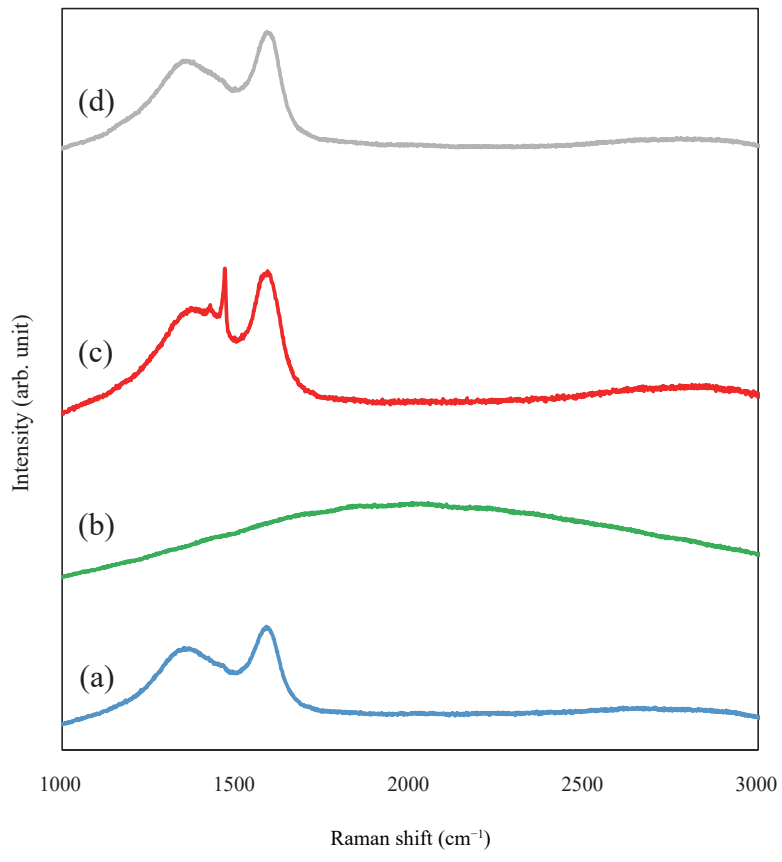

Fig. 8. (Color online) Raman scattering spectra of (a) the $\mathrm{C}_{60}$ film exposed to UV irradiation at $500 \mathrm{~W}$ for $24 \mathrm{~h}$ in ambient atmosphere, (b) $\mathrm{C}_{60}$ film exposed to UV irradiation at $700 \mathrm{~W}$ for $120 \mathrm{~h}$ in ambient atmosphere, (c) $\mathrm{C}_{60}$ film exposed to UV irradiation at $500 \mathrm{~W}$ for $24 \mathrm{~h}$ in a vacuum of $10^{-1} \mathrm{~Pa}$, and (d) $\mathrm{C}_{60}$ film exposed to UV irradiation at $700 \mathrm{~W}$ for $18 \mathrm{~h}$ in a vacuum of $10^{-1} \mathrm{~Pa}$.

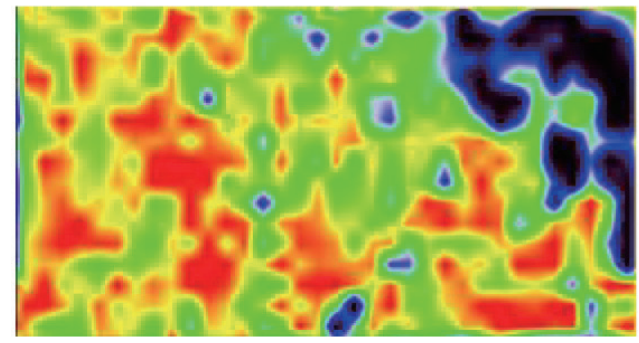

(b)

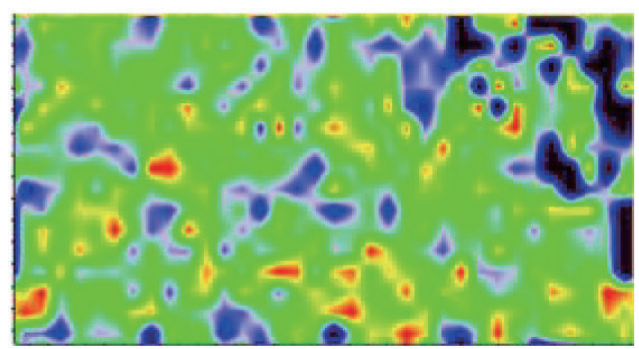

(c)

Fig. 9. (Color online) Raman scattering spectrum mapping of the $\mathrm{C}_{60}$ film heat treated using the $\mathrm{Cu}$ catalyst. UV irradiation was conducted at $500 \mathrm{~W}$ for $24 \mathrm{~h}$ in ambient atmosphere. (a) The mapping of the $\mathrm{Cu}$ catalyst, (b) mapping of the graphitic band, and (c) mapping of the disorder band.

$\mathrm{C}_{60}$ molecules under $\mathrm{UV}$ irradiation, so that polymerization of the $\mathrm{C}_{60}$ molecules did not take place even in vacuum.

The second reason is the influence of the particle size of the $\mathrm{Cu}$ catalyst on the domain size of the graphitic film. The $\mathrm{Cu}$ catalyst was approximately $300 \mathrm{~nm}$ thick. The heat treatment at $873 \mathrm{~K}$ for $10 \mathrm{~min}$ led to insufficient $\mathrm{Cu}$ grain growth, which in turn resulted in the formation of a graphitic film with small domains. Therefore, the film structure as predicted by Raman spectroscopy can be considered to be amorphous. Furthermore, it is possible that the heat treatment temperature was inadequate for the interfacial reaction between the carbon atoms and the $\mathrm{Cu}$ catalyst. In a general CVD process, the synthesis of graphene usually takes place at around $1273 \mathrm{~K} .{ }^{(30)}$

Interestingly, the film shown in Fig. 8(a) exhibited optical transparency unlike the other films. The Raman spectrum mapping of the film shown in Fig. 9 revealed that the graphitic region was separated from the $\mathrm{Cu}$ region. This result suggests that once the graphitic structure was formed 
on the $\mathrm{Cu}$ catalyst, the catalyst migrated. Furthermore, some of the separated $\mathrm{Cu}$ was evaporated from the substrate, which facilitated the formation of an optically transparent film, as shown in Fig. 8(a). Under these experimental conditions, the reproducibility of the film was low. It is possible to form optically transparent films directly on glass substrates if the mechanism of phase transformation of $\mathrm{C}_{60}$ molecules on $\mathrm{Cu}$ catalysts and the interfacial reactions between them can be precisely controlled.

\section{Summary}

In this study, the effect of UV irradiation and metal catalysts on the formation of $\mathrm{C}_{60}$ films was investigated to prepare an optically transparent graphitic film on a glass substrate. UV irradiation of the $\mathrm{C}_{60}$ films caused a phase transformation by either polymerization or decomposition of the $\mathrm{C}_{60}$ molecules depending on the atmosphere in which the irradiation was carried out. In the $\mathrm{Ni}$ process, the polymerization of $\mathrm{C}_{60}$ molecules by $\mathrm{UV}$ irradiation in vacuum contributed to the formation of a graphitic film on the glass substrate. The structural control of $\mathrm{C}_{60}$ film used as a solid carbon source was a key technology for the preparation of the film. The $\mathrm{Cu}$ process failed to yield a homogeneous optically transparent film with a graphitic structure. However, an interesting phenomenon of phase separation of the graphitic and $\mathrm{Cu}$ regions was observed. The exploration of the mechanism of the migration and vaporization of the copper catalyst may contribute to a novel technique for the direct formation of transparent electroconductive films on glass substrates. Detailed investigations on the optimum thickness of the $\mathrm{C}_{60}$ film or the catalyst film and the crystallinity of the carbon films obtained is required.

\section{Acknowledgments}

We would like to thank Editage (www.editage.jp) for English language editing.

\section{References}

1 L. Gengchiau, N. Neophytos, M. S. Lundstrom, and D. E. Nikonov: IEEE Trans. Electron Dev. 54 (2007) 677.

2 V. Ryzhii, M. Ryzhii, and T. Otsuji: Appl. Phys. Express 1 (2008) 013001.

3 B. Obradovic, R. Kotlyar, F. Heinz, P. Matagne, T. Rakshit, M. D. Giles, M. A. Stettler, and D. E. Nikonov: Appl. Phys. Lett. 88 (2006) 142102.

4 J. Kim, M. Ishihara, Y. Koga, K. Tsugawa, M. Hasegawa, and S. Iijima: Appl. Phys. Lett. 98 (2011) 091502.

5 A. K. Geim: Science 324 (2009) 1530.

6 K. I. Bolotin, K. J. Sikes, Z. Jiang, M. Klima, G. Fudenberg, J. Hone, P. Kim, and H. L. Stormer: Solid State Commun. 146 (2008) 351.

7 R. R. Nair, P. Blake, A. N. Grigorenko, K. S. Novoselov, T. J. Booth, T. Stauber, N. M. R. Peres, and A. K. Geim: Science 320 (2008) 1308.

8 X. Li, W. Cai, J. An, S. Kim, J. Nah, D. Yang, R. Piner, A. Velamakanni, I. Jung, E. Tutuc, S. K. Banerjee, L. Colombo, and R. S. Ruoff: Science 324 (2009) 1312.

9 S. Bae, H. Kim, Y. Lee, X. Xu, J. Park, Y. Zheng, J. Balakrishnan, T. Lei, H. R. Kim, Y. I. Song, Y. Kim, K. S. Kim, B. Özyilmaz, J. Ahn, B. Hong, and S. Iijima: Nat. Nanotechnol. 5 (2010) 574.

10 T. Terasawa and K. Saiki: Carbon 50 (2012) 869.

11 A. Kumar, A. A. Voevodin, D. Zemlyanov, D. N. Zakharov, and T. S. Fisher: Carbon 50 (2012) 1546.

12 T. Kobayashi, M. Bando, N. Kimura, K. Shimizu, K. Kadono, N. Umezu, K. Miyahara, S. Hayazaki, S. Nagai, Y. Mizuguchi, Y. Murakami, and D. Hobara: Appl. Phys. Lett. 102 (2013) 023112.

13 T. Yamada, M. Ishihara, J. Kim, M. Hasegawa, and S. Iijima: Carbon 50 (2012) 2615. 
14 T. Yamada, J. Kim, M. Ishihara, and M. Hasegawa: J. Phys. D: Appl. Phys. 46 (2013) 063001.

15 T. Yamada, M. Ishihara, and M. Hasegawa: Thin Solid Films 532 (2013) 89.

16 Z. Sun, Z. Yan J. Yao, E. Beitler, Y. Zhu, and J. M. Tour: Nature 468 (2010) 549.

17 R. Arai, Y. Furukawa, M. Morisima, and T. Kuzumaki: J. Jpn. Inst. Met. Mater. 77 (2013) 59.

18 P. Zhou, A. M. Rao, K. A. Wang, J. D. Robertson, C. Eloi, M. S. Meier, S. L. Ren, X. X. Bi, P. C. Eklund, and M. S. Dresselhaus: Appl. Phys. Lett. 60 (1992) 2871

19 A. M. Rao, P. Zhou, K. A. Wang, G. T. Hager, J. M. Holden, Y. Wang, W. T. Lee, X. X. Bi, P. C. Eklund, D. S. Cornett, M. A. Duncan, and I. J. Amster: Science 259 (1993) 955.

20 A. Rao, P. C. Eklund, U. D. Venkateswaran, J. Tucker, M. A. Duncan, G. M. Bendele, P. W. Stephens, J.L. Hodeau, L. Marques, M. Nunez-Regueiro, L. O. Bashkin, E. G. Ponyatovsky, and A. P. Morovsky: Appl. Phys., A 64 (1997) 231.

21 J. Onoe, T. Nakayama, M. Aono, and T. Hara: Appl. Phys. Lett. 82 (2003) 595.

22 V. A. Karachevtsev, P. V. Mateichenko, N. Yu. Nedbailo, A. V. Peschanskii, A. M. Plokhotnichenko, O. M. Vovk, E. N. Zubarev, and A. M. Rao: Carbon 42 (2004) 2091.

23 E. Alvarez-Zauco, H, Sobral, E. V. Basiuk, J. M. Saniger-Blesa, and M. Villagran-Muniz: Appl. Surf. Sci. 248 (2005) 243.

24 P. C. Eklund, A. M. Rao, P. Zhou, Y. Wang, and J. M. Holden: Thin Solid Films 257 (1995) 185.

25 A. M. Rao, K. A. Wang, J. M. Holden, Y. Wang, P. Zhou, P. C. Eklund, C. C. Eloi, and J. D. Robertson: J. Mater. Soc. 8 (1993) 2277.

26 M. Wohlers, H. Werner, T. Belz, T. Ruhle, and R. Schlogl: Mikrochima Acta 125 (1997) 401.

27 T. L. Makarova, K. H. Han, P. Esquinazi, R. R. da Silva, Y. Kopelevich, I. B. Zakharova, and B. Sundqvist: Carbon 41 (2003) 1575.

28 K. Matsuishi, T. Ohno, N. Yasuda, T. Nakanishi, S. Onari, and T. Arai: J. Phys. Chem. Solids 58 (1997) 1747

29 A. Ito, T. Morikawa, and T. Takahashi: Chem. Phys. Lett. 211 (1993) 333.

30 C. Mattevi, H. Kim, and M. Chhowalla: J. Mater. Chem. 21 (2011) 3324. 